\title{
COMMENTARY \\ Proton pump inhibitors and the risk of Clostridium difficile- associated disease: further evidence from the community
}

\author{
Richard Cunningham
}

$\infty \quad$ See related article page 745

$\mathrm{C}$ lostridium difficile-associated disease (CDAD) is recognized as a major avoidable cause of morbidity and mortality among patients in hospital. Demographic changes and transfer of medical and surgical care into the community mean that the distinction between community- and hospital-acquired CDAD is becoming increasingly blurred. An increase in reported cases of CDAD, high profile outbreaks in Canada, the United States and the United Kingdom, and the consequent media and political focus on the problem, all contribute to a perception that the incidence and severity of CDAD is increasing. Published studies suggest that this perception is correct. ${ }^{1-3}$

Classic risk factors for CDAD include broad-spectrum antibiotic use, increasing age and prolonged hospital stay. These factors are universally agreed to be important, although fundamental issues, such as which antibiotics are the most important, what is the physiologic basis for increased risk in the elderly population and does length of hospital stay reflect longer exposure or higher comorbidity, remain unresolved. Outside these risk factors, there is little consensus on any aspect of pathogenesis. Even when sophisticated molecular typing and studies of pathogenesis have been applied to clonal outbreaks, controversy has ensued over the relative contribution of antibiotic resistance, environmental and hand hygiene, and isolation of cases. ${ }^{4-7}$ Add to this increasingly polarized debate the issue of proton pump inhibitors. In some studies, use of these drugs has been found to be second only to antibiotic therapy as a risk factor for $\mathrm{CDAD},{ }^{8-10}$ whereas other researchers have dismissed use of proton pump inhibitors as merely reflecting confounding variables such as age and prolonged hospital stay. ${ }^{5}$

Why is there such a lack of consensus when results from large, carefully conducted studies are analyzed using the most sophisticated statistical techniques? Perhaps the problem is the complex pathogenesis of CDAD. Unlike classic gastrointestinal disease such as infection with Shigella dysenteriae, infection and symptomatic disease are not overtly linked. Ingested Clostridium difficile spores or vegetative cells may be killed by gastric acid or fail to colonize in the bowel in detectable numbers. If they do establish colonization, they may not produce toxins. Even if they are toxigenic, no ill effects may be apparant unless the normal bowel flora is disturbed by antibiotics or cytotoxic chemotherapy. Furthermore, a prompt humoural immune response to toxin A is correlated with asymptomatic carriage. Reinfection with the same or a different strain may occur at any time. Can we really expect epidemiologic studies to clarify the root causes of such a complex interaction between host, pathogen and environment?

\section{Can epidemiologic studies really clarify the causes of such a complex interaction between host, pathogen and environment?}

A better approach may be to study patients in a less complex environment, such as the community rather than the hospital setting. In this issue, ${ }^{11}$ Dial and colleagues report a case-control study looking at the use of proton pump inhibitors and the risk of community-acquired CDAD using the well-validated UK General Practice Resarch Database. To avoid potential recording bias, which may have occurred in a previous study in which clinical diagnosis and laboratory results were used to identify cases, the authors this time used the novel approach of considering oral vancomycin therapy as a proxy for CDAD. This is reasonable, because CDAD is the only indication for this antibiotic by this route. Conditional logistic regression analysis was used to control for the usual covariates. The results were consistent with those from previous studies involving patients in acute hospital and community settings: exposure to a proton pump inhibitor in the 90 days before prescription of oral vancomycin therapy was associated with an increased risk of CDAD (odds ratio [OR] 3.5, 95\% confidence interval [CI $2.3-5.2$ ). Prior exposure to antibiotic therapy was also a significant risk factor (OR 8.2, 95\% CI 6.2-I0.9).

Does the study by Dial and colleagues finally settle the issue of whether proton pump inhibitors are causally associ- 
ated with CDAD? Unfortunately not, the authors are measured in their discussion of their findings and simply state that their results add weight to the evidence for an association. It is something of a cliché to conclude that further research is required; however, opinions are so polarized on this issue that only a prospective, blinded, controlled interventional study is likely to resolve it. Proton pump inhibitors are widely overused in the United Kingdom, and a pilot study in Plymouth, England, found that a significant proportion of patients admitted to hospital were taking these drugs with no clear indication for their use. The opportunity exists for a randomized interventional study to assess the impact of stopping or continuing treatment with proton pump inhibitors at the time of admission to hospital on the subsequent development of CDAD. A study of this kind would not be easy to set up and would likely not attract funding from the pharmaceutical industry, but it could provide vital intelligence in the battle against this infection. Careful antibiotic prescribing and good hygiene are essential, but recent experience suggests that they may not be enough to turn the tide.

This article has been peer reviewed.

Richard Cunningham is with the Department of Microbiology, Derriford Hospital, Plymouth, UK.

Competing interests: None declared.

\section{REFERENCES}

I. Archibald LK, Banerjee SH, Jarvis WR. Secular trends in hospital-acquired Clostridium difficile disease in the United States, I987-200I. J Infect Dis 2004;I89: I585-9.

2. Pépin J, Valiquette L, Alary ME, et al. Clostridium difficile-associated diarrhea in a region of Quebec from I99I to 2003: a changing pattern of disease severity. CMAJ 2004; I7I(5):466-72.

3. Health Protection Agency. Reports of Clostridium difficile isolated from faecal specimens under the voluntary reporting scheme: England, Wales, and Northern Ireland I990-2004. London: The Agency. Available: www.hpa.org.uk/infections /topics_az/clostridium_difficile/vol_data.htm (accessed 2006 Aug 17).

4. Loo VG, Poirier L, Miller MA, et al. A predominantly clonal multi-institutional outbreak of Clostridium difficile-associated diarrhea with high morbidity and mortality. N Engl J Med 2005;353:2442-9.

5. Pépin J, Saheb N, Coulombe M, et al. Emergence of fluoroquinolones as the predominant risk factor for Clostridium difficile associated diarrhea: a cohort study during an epidemic in Quebec. Clin Infect Dis 2005;4I:I254-60.

6. Beaulieu M, Thirion DJG, Williamson D, et al. Clostridium difficile-associated diarrhea outbreaks: The name of the game is isolation and cleaning. Clin Infect Dis 2006;42:725.

7. Weiss K. Poor infection control, not fluoroquinolones, likely to be primary cause of Clostridium difficile-associated diarrhea outbreaks in Quebec. Clin Infect Dis 2006;42:725-7.

8. Cunningham R, Dale B, Undy B, et al. Proton pump inhibitors as a risk factor for Clostridium difficile diarrhoea. J Hosp Infect 2003;54:243-5.

9. Dial S, Alrasadi K, Manoukian C, et al. Risk of Clostridium difficile diarrhea among hospital inpatients prescribed proton pump inhibitors: cohort and casecontrol studies. CMAJ 2004; I7 I:33-8.

Io. Dial S, Delaney JAC, Barkun AN, et al. Use of gastric acid-suppressive agents and the risk of community acquired Clostridium difficile-associated disease. JAMA 2005;294:2989-95.

II. Dial S, Delaney JAC, Schneider V, et al. Proton pump inhibitor use and risk of community-acquired Clostridium difficile-associated disease defined by prescription for oral vancomycin therapy. CMAJ 2006;175(7):745-8.

Correspondence to: Dr. Richard Cunningham, Department of Microbiology, Derriford Hospital, Plymouth PL6 8DH, UK 